\title{
ENERGY STORAGE MANAGEMENT FOR GRID OPERATION PURPOSES
}

\author{
Ricardo Jorge SANTOS \\ EDP Distribuição - Portugal \\ ricardojorge.santos@edp.pt \\ Clara GOUVEIA \\ INESC TEC - Portugal \\ clara.s.gouveia@inesctec.pt \\ José DAMÁSIO \\ Siemens - Portugal \\ jose.damasio@siemens.com
}

\author{
Ricardo ANDRE \\ EDP-NEW R\&D - Portugal \\ ricardo.andre@edp.pt \\ António ARAUJO \\ EDP-Distribuição - Portugal \\ antonio.araujo@edp.pt \\ Guillermo BRAVO \\ INDRA - Spain \\ gbravo@indra.es
}

\author{
Ricardo BESSA \\ INESC TEC - Portugal \\ ricardo.j.bessa@inesctec.pt \\ Filipe GUERRA \\ EDP-NEW R\&D \\ filipe.guerra@edp.pt \\ Jean SUMAILI \\ INESC TEC - Portugal \\ jean.sumaili@inesctec.pt
}

\begin{abstract}
The Horizon 2020 Storage ENabled SustaInable energy for BuiLdings and communitiEs (SENSIBLE) project is currently looking at the integration of small-scale storage technologies in buildings and distribution networks. In the demonstration site of the SENSIBLE project, EDP has already installed an experimental storage system supplying a university campus in MV. It was mainly designed to increase service quality to the university by providing backup power in the event of $M V$ grid failure, but it can also control voltage profile and conduct peakshaving. In parallel, small-scale storage is being also installed at the LV level by SENSIBLE. For these new grid assets, the SENSIBLE project is implementing a use case for centralized control approach that guarantees a coordinated operation of $M V$ and LV storage. Furthermore, adding a MV switchgear, the resulting system will be able to isolate from the main grid thus effectively working as a microgrid with $M V$ and $L V$ Storage, PV generation and residential/commercial loads. This paper presents an overview of the technologies and software that will enable new grid support functions from small-scale storage.
\end{abstract}

\section{INTRODUCTION}

\section{SENSIBLE Project}

The ambitious 20-20-20 targets of the European Union (EU) have been fostering the development of several projects focusing on the development of solutions to comply with these goals. SENSIBLE - Storage ENabled SustaInable energy for BuiLdings and communitiEs is a Horizon 2020[1] funded innovation action aiming at integrating small-scale electro-chemical, electromechanical and thermal storage technologies, together with Distributed Renewable Energy Sources (DRES), into distribution grid, homes and buildings. The benefits of storage integration will be demonstrated in three sites: Évora (Portugal), Nottingham (UK) and Nuremberg (Germany). The aim is to create value for distribution grid operation, market players and end-users. Moreover, flexibility-based business models will be proposed based on connecting the local storage capacity with the energy markets, at the individual and aggregated level. SENSIBLE will also conduct life cycle analyses and assess the socio-economic impact of small-scale storage integrated in buildings and distribution grids.

The Portuguese demonstrator is located in a rural area with 238 clients connected to Low Voltage (LV) grid, with no redundancy, two secondary substations of $250 \mathrm{kVA}$ and a client-owned secondary substation. The main objective of this demonstrator is to test new grid strategies and applications for tackling the technical challenges resulting from the large scale integration of micro/mini renewable generation, together with the new load power consumption profiles, resulting from the deployment of demand side management and self-consumption strategies.

In the Évora demo site, the storage units connected to secondary substations, will be operated to improve the technical operation of both LV and MV networks, namely by providing losses minimization or voltage regulation. At the same time, storage units will provide backup power capacity to mitigate the effects of voltage sags and service interruptions as a consequence of faults. Figure 1, illustrates a very simplified grid architecture of the Évora demonstrator infrastructure to be implemented until the end of 2016.

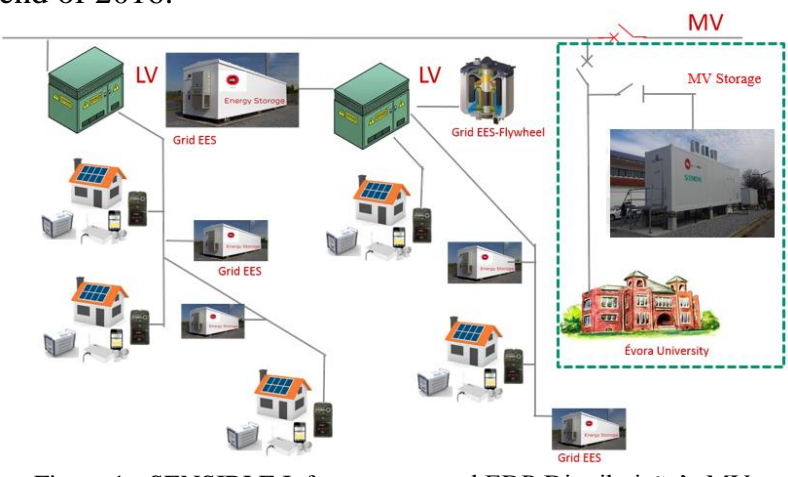

Figure 1 - SENSIBLE Infrastructure and EDP Distribuição's MV Storage.

As shown in Figure 1, the demonstrator includes electrochemical storage and a flywheel, residential storage and PV. Smart meters are also installed in every consumer, as well as home automation systems in the households equipped with controllable loads. 
The data provided by the smart metering infrastructure will enable the implementation of a set of grid applications that are being developed in the context of the project, according to the ICT architecture represented in Figure 2. The components of the Évora demo can be grouped according to DSO Infrastructure, Independent Actors, Market Operators and Client/Retailer Infrastructure. The DSO devices include, among others, smart meters, DSO database that collects all the data communicated via Distribution Transformer Controller (DTC) and acts as a middleware between the downstream LV grid and the upstream distributed Real Time Platform.

EDP's already existing MV voltage system is designed to enable the power backup for the University of Évora and support grid management functions. This system is not represented in the above figure 1 , since it was not initially involved in the SENSIBLE project. However, as will be thoroughly explained in the following sections, a more ambitious and valuable proposal for the use of the MV storage is now being considered, and will be the main focus of this paper.

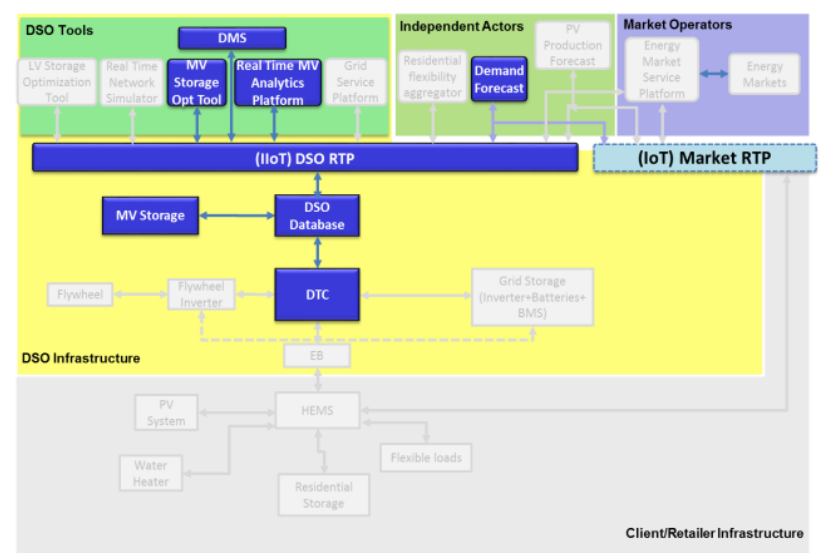

Figure 2 - SENSIBLE ICT Architecture.

\section{Voltage Storage Project}

\section{Project overview}

EDP Distribuição, the main Portuguese DSO, has been studying storage technologies for the last few years. The knowledge and experience gathered led the company to install its first MV storage project located inside the Évora University campus of Mitra, in December of 2015 [2]. The project consists, as depicted in Figure 3, of a 30 tons container with Lithium Ion batteries of $472 \mathrm{~kW} / 360 \mathrm{kWh}$, power electronics and battery management system, firing extinguishing systems, air conditioned (AC), MV power cells and a dry-type transformer, just to name the most important components.

This Electric Energy Storage (EES) point of common coupling is on the MV side $(15 \mathrm{kV})$ of the $15 / 0.4-\mathrm{kV}$ secondary substation that supplies the customer. Despite its stand-alone nature, the system is connected to EDP Distribuição's dispatch center through IEC 60870-104

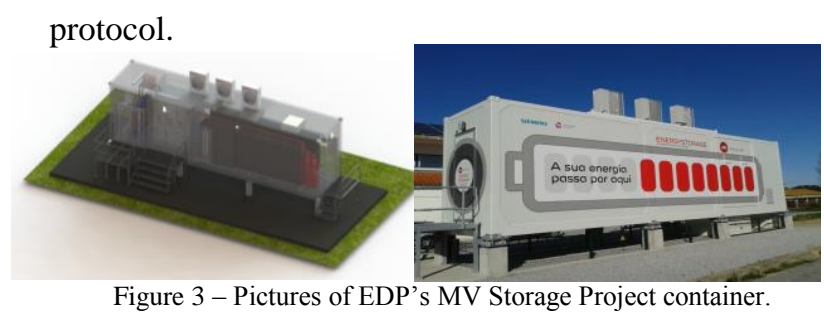

The system contains eight lithium battery rack modules, four three-phase inverters coupled with output filters and a three-winding $\mathrm{MV} / \mathrm{LV}$ transformer. The three winding transformer (30/15/0.4 kV) allows the connection of the EES system to both $30-\mathrm{kV}$ and $15-\mathrm{kV}$ MV networks to cater for network voltage upgrades or system relocation. This pilot project is focused on delivering solutions for EDP Distribuição main technical challenges: increase grid reliability, by providing backup to the Évora's university campus, in case of a loss of the MV grid. The project also provides other network support services such as fault ridethrough, voltage control and peak shaving for loss reduction (Figure 4).

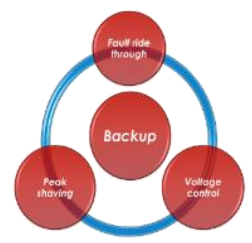

Figure 4 - Main present MV storage functions.

In the future, the EES system will need to be fully integrated into a higher hierarchical control layer that provides the necessary data to the automation and artificial intelligence of the system, moving toward a smart storage system.

To achieve the above mentioned objectives, the sizing of the system took into consideration both power and energy requirements in accordance with the customer's demand profile. Two criteria were established to evaluate the sizing needs of the system:

- Electrical energy storage capacity: autonomy of one hour versus a 30-minute;

- Power: maximum annual peak load versus conservative $^{1}$ power value.

The sizing requirements of the system were based on the customer's needs, assessed by the historical record of the annual number and duration of outages as well as the customer's yearly consumption profile. From the Outage's duration analysis, it was possible to conclude EES energy capacity should be sized to 30 minutes, rather than 1 hour, because this option covered approximately $95 \%$ of the power outage events.

When analyzing the customer's consumption profile, it was necessary to take into account the huge difference between the working day and non-working day profile, which represented $49 \%$ of the year. This detail is 
particularly relevant because the EES system will be connected at the end of a capillary region of the distribution network and, therefore, be subject to a significant influence of network losses and load profile variations.

Based on the previous data as well as the link between the customer's average consumption together with the annual and network outage probabilistic profile, the undertaken studies concluded that the best system sizing - taking into consideration EES performance versus investment - was as follows:

- EES power corresponding to the customer's yearly average power demand plus standard deviation $(393 \mathrm{~kW})$;

- EES electrical energy capacity of 30 minutes at rated power (196 kWh).

With these requirements, it is possible to provide backup for $91 \%$ to $98 \%$ of the time considering a random failure, thus reducing the investment in EES by $11 \%$ when compared to full power backup EES sizing (rated power at the customer's annual maximum peak load). Furthermore, based on the studies, the average network losses would be reduced by $14.2 \%$ in addition to a decrease in overall voltage deviations.

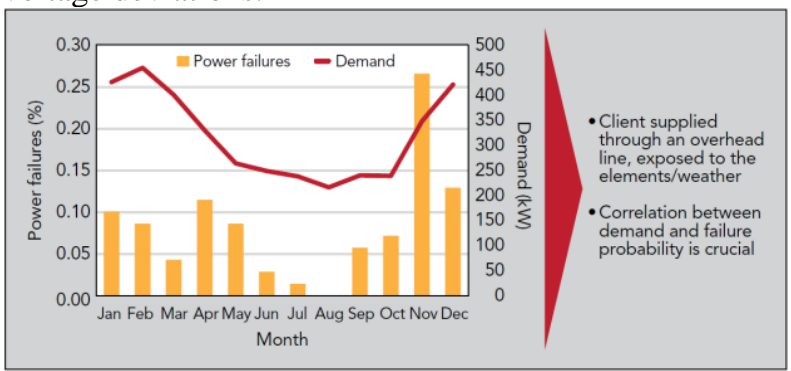

Figure 5 - Probability of power failures and load demand.

EDP Distribuição is predicting future developments to optimize the EES system. Local functions, such as backup and fault ride-through, can be managed locally. Nonetheless, network management functions, like loss reduction and voltage control, should be managed from the MV feeder point of view, which requires the development of a higher hierarchical level control system that can do the following:

- Forecast the customer's consumption profile;

- Forecast the EES consumption profile of other MV feeders;

- Boost network operation through power flow optimization;

- Define EES power-quality set points.

\section{INTER PROJECT COOPERATION}

This paper focuses on the cooperation and synergies between SENSIBLE and EDP Distribuição's MV storage. The resulting grid configuration is illustrated in Figure 1, differs from the initial SENSIBLE configuration by including the MV storage and a MV switchgear to allow isolation (islanding) from the upstream MV grid.

As already stated, the main objective of the MV storage installed in the client's secondary substation is to provide backup capacity to Évora University for 30 minutes. However, there will be periods of time in which the load demand will be significantly lower, thus the exceeding battery capacity can be used to optimize the operation of the MV network, in the context of SENSIBLE project. If a fault occurs in the network (upstream to the MV switchgear represented in Figure 1), the entire system will be operated in islanded mode considering the storage capacity and the inverters grid forming capabilities of the units installed in the two secondary substations and the MV Storage. This situation will require the coordination of MV and LV switchgears, power electronics, command and control and protection schemes on the two voltage levels.

The high level coordination, optimization and security of the demonstrator will be ensured through increased monitoring and control capabilities provided by the ICT infrastructure represented in Figure 2. During interconnected islanding mode, a multi-period optimal power flow (OPF) algorithm will define the storage operating strategy for a pre-defined time horizon (e.g., next hours, day) in order to minimize the power losses and operating costs (including degradation costs if available), while respecting the technical constraints of the network and considering the future states of the MV grid. A detailed description of the OPF tool is provided next.

\section{OPTIMIZATION OF THE EES OPERATION}

The proposed model is formulated as a unique optimization problem that considers the operation for the entire period considering the desired time resolution. In the preliminary tests, a full day of 24 hours with hourly resolution has been considered. The multi-period OPF is able to provide the optimal management of the storage device taking into account the forecasted behavior of consumers and local generators connected to the distribution system. In addition to the classical constrains of the OPF problem, storage related constraints were also integrated. From an energy balance point of view, the efficiency of the storage process needs to be considered. This includes discontinuity in the storage model and in the corresponding restrictions. In this project, the storage device has been modelled with four different elements with continuous behaviour (Figure 6):

- a load during the charging period $\left(P_{t}^{c h \text { arg } e} \leq 0\right)$,

- a generator for power injection $\left(P_{t}^{\text {discharge }} \geq 0\right)$

- two loads emulating the storage losses during the charging and discharging of the battery $\left(L_{t}^{\text {charge }} \leq 0, L_{t}^{\text {discharge }} \leq 0\right)$. 


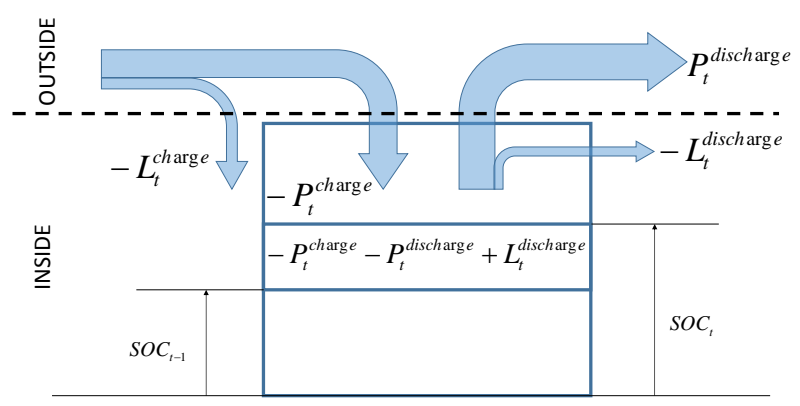

Figure 6 - Storage device model.

The storage device losses can be written as following:

- Charging losses:

$$
L_{t}^{\text {charge }}=\frac{\left(1-\varepsilon^{\text {charge}}\right)}{\varepsilon^{\text {charge }}} \times P_{t}^{\text {charge }}
$$

- Discharging losses:

$$
L_{t}^{\text {discharge }}=\frac{\left(\varepsilon^{\text {discharge }}-1\right)}{\varepsilon^{\text {discharge }}} \times P_{t}^{\text {discharg } e}
$$

where

$\varepsilon^{\text {charge }}$ is the charge efficiency,

$\varepsilon^{\text {discharg } e}$ is the discharge efficiency,

$P_{t}^{\text {charge }}$ is the charge power on time $t$,

$P_{t}^{\text {discharge }}$ is the injection power on time $t$,

$L_{t}^{c h a r g e}$ is the loss during the charge on time $t$, and

$L_{t}^{\text {discharge }}$ is the loss during the injection on time $t$.

In order to manage the EES it is also necessary to take into account its State Of the Charge (SOC). The value of the SOC for each time instant was considered as well as the interdependency between periods as described in the following equation.

$$
S O C_{t}=S O C_{t-1}-P_{t}^{l o a d}-P_{t}^{i n j}+L_{t}^{i n j}
$$

Where

$S O C_{t}$ is the state of charge on time $t$, and

$S O C_{t-1}$ is the state of charge on time $t-1$.

Other constraints associated with the SOC have also been introduced in the OPF. The limits for the SOC are shown in (4), where $S O C^{\max }$ is the capacity of the storage device and $S O C^{\min }$ is the lower bound of the state of charge defined by the fact that the continuity of the supply must be guaranteed for a minimum time in case of failure of the main grid.

$$
S O C^{\min } \leq S O C_{t} \leq S O C^{\max }
$$

The net injection of the storage device can be written as following:

$$
P_{t}^{n e t}=P_{t}^{\text {discharge }}+L_{t}^{\text {discharge }}+P_{t}^{\text {charge }}+L_{t}^{\text {charge }}
$$

and where $P_{t}^{\text {net }}$ is the balance representation of the storage device.

The objective function considered, here, is the minimization of the consumption from the main grid. However, the algorithm is flexible enough to include other objective functions.

\section{CONCLUSION}

The proposed cooperation between the two projects is expected to create significant synergies.

On the one hand, the ongoing MV Storage project is already enabling the collection of technical data on power conversion systems performance, battery management and degradation profiles or legal and regulatory issues. While SENSIBLE prepares the deployment of its assets, the MV project will continue to gather information on system efficiency and storage specific operational challenges like the ones related to electric protection systems in low short circuit systems.

On the other hand, SENSIBLE will provide an opportunity to develop new computational tools aiming at storage operation optimization versus a localized control with high dependence on manual operations and integrate this new assets in the normal and emergency operation of the MV and LV distribution grids.

\section{ACKNOWLEDGEMENTS}

This work is being carried out as a part of the SENSIBLE project (Storage ENabled SustaInable energy for BuiLdings and communitiEs - www.h2020-projectsensible.eu) that has received funding from the European Union's Horizon 2020 research and innovation program under grant agreement No 645963.

\section{REFERENCES}

[1] Webpage project SENSIBLE http://www.h2020-projectsensible.eu/sensible/index.aspx

[2] Pedro Carreira, Ricardo André, Ricardo Santos, Gonçalo Faria, 2006, "EDP Rolls Out Smart Storage System", Transmission \& Distribution World. vol. 68, $\mathrm{N}^{\circ} 2,49-53$.

\footnotetext{
${ }^{1}$ Average power value plus standard deviation
} 